\title{
Primary Anorectal Amelanotic Melanoma: The First Case Report from Saudi Arabia
}

\author{
Khaled Ali Baniyaseen ${ }^{1}$, Muhammad Saeed ${ }^{2}$, Ahmed Omar Albonni ${ }^{3}$, \\ Bothaina Mohammed Abdulshakour ${ }^{4}$, Ghida Dairi ${ }^{5}$, \\ Faisal A. Al-Allaf ${ }^{6,7}$, Mohiuddin M. Taher ${ }^{6,7, *}$
}

1. Histopathology Division, Al-Noor Specialist Hospital, Makkah, Saudi Arabia

2. Faculty of Medicine, Umm-Al-Qura University, Makkah, Saudi Arabia

3. Histopathology Division, King Fahad Central Hospital, Jazan, Saudi Arabia

4. Department of Radiology, Al-Noor Specialty Hospital, Makkah, Saudi Arabia

5. Medicine and Medical Sciences Research Center, Deanship of Scientific Research, Umm-Al-Qura University, Makkah, Saudi Arabia

6. Department of Medical Genetics, Umm-Al-Qura University, Saudi Arabia

7. Science and Technology Unit, UmmAl-Qura University, Makkah, Saudi Arabia

\section{* Corresponding Author:}

Mohiuddin M. Taher, Ph.D.

College of Medicine, Al-Abidiya Campus, Umm-Al-Qura University, Taif Road, Makkah-21955, Saudi Arabia

Tel: + 966580149556

Fax: + 966125586279

Email: TMMohiuddin@uqu.edu.sa

Received: 20 Dec. 2018

Accepted: 19 May 2019

\section{ABSTRACT}

Anorectal melanomas are exceptionally uncommon and only $30 \%$ of anorectal melanomas are amelanotic. We report here a case of an anorectal amelanotic melanoma in a female patient. An 84-year-old patient complained of anal mass for 3 months. On examination, there was a 7.0 $\mathrm{cm}$ mass prolapsing through the anus that was pale-pink in color. Abdominal, pelvic, and chest computed tomography (CT) showed rectal wall thickening with an eccentric polypoid soft tissue density mass, and left inguinal and presacral lymph node enlargement along with a small nodule in the lower lobe of the left lung, likely representing metastatic deposit. Microscopic examination revealed a piece of skin with hyperplastic squamous epithelium with surface ulceration. The dermis and underlining tissue were showing infiltration by malignant sheets and nests of ovoid and spindle shape cells with prominent nucleolus and high mitotic s. Immuno-staining for HMB-45, S-100, and Melan-A was positive, and it was negative for P63, CK 5/6, and Pan-CK, thus confirming it as an anorectal amelanotic melanoma, and not an epithelial tumor. This is the first case of an amelanotic anorectal melanoma reported from Saudi Arabia.

\section{KEYWORDS:}

Anorectal cancer, Anorectal melanoma, Amelanotic melanoma, Lung metastasis, Saudi Arabia

Please cite this paper as:

Baniyaseen KA, Saeed M, Albonni AO, Abdulshakour BM, Dairi G, Al-Allaf FA, Taher MM. Primary Anorectal Amelanotic Melanoma: The First Case Report from Saudi Arabia. Middle East J Dig Dis 2019;11:166-173. doi: 10.15171/mejdd.2019.144.

\section{INTRODUCTION}

Anorectal melanomas are exceptionally uncommon. It accounts for less than $1.0 \%$ of anorectal malignancies and around $0.3 \%$ of all melanomas. ${ }^{1}$ Since, most of the cases with anorectal melanomas already have distant metastases at the time of presentation, the prognosis of this disease is poor with a median post-treatment survival time of less than 2 years and the 5-year survival rate of less than $20 \%{ }^{1,2}$ Amelanotic melanoma represents about $2-8 \%$ of all melanomas, almost $30 \%$ of anorectal melanomas are amelanotic, and they are distinct because they contain a little or no-pigmentation. ${ }^{3-6}$ However, the exact prevalence of this malignancy may be higher because this type of melanoma is difficult to diagnose. ${ }^{7,8}$ Amelanotic melanomas of the anorectum are extremely rare; only 20 cases of amelanotic melanomas of the anorectum have been reported in literature. Amelanotic or hypomelanotic melanomas 
are a subtype of melanomas with no pigmentation and minimally pigmented on clinical examination. Uncommonly, this malignancy lacks melanin pigment, complicating detection. Presenting complaints are non-specific rectal bleeding, pain, itching, or incontinence, mimicking more common disorders, and if malignancy is not suspected these melanomas can be misdiagnosed..$^{3,4,8,9}$ Rectal bleeding is the most common symptom in anorectal melanoma, and for this reason this tumor can be misdiagnosed as simple hemorrhoids, which delays the diagnosis. ${ }^{10,11}$

Amelanotic melanomas are considered as the great masqueraders in dermatology. ${ }^{12}$ Several cases of initial misdiagnosis were reported by pathologists, which upon careful investigations and rechecking for the melanoma markers turned out to be amelanotic melanomas. ${ }^{13}$ There were reports of amelanotic melanoma cases that were initially misdiagnosed as a basal cell carcinoma, ${ }^{12}$ pyogenic granuloma, ${ }^{14,15}$ poorly differentiated adenocarcinoma of the rectum, ${ }^{16,17}$ Bowen's disease, ${ }^{18}$ presenting as contact dermatitis, ${ }^{19}$ simulating juvenile xanthogranuloma, ${ }^{20}$ and as otitis media. ${ }^{21}$ Using the histological criteria alone, differentiation of amelanotic anorectal melanoma from other malignant tumors is difficult, and immunostains are of important help to make the diagnosis accurately.22 Abnormal expression of immunohistochemical stains such as vimentin, cytokeratin, and c-Kit (CD117) further increases the risk of misdiagnosis. ${ }^{23}$

Due to the aggressive nature and rarity of the disease, there are no separate guidelines for staging of the amelanotic anorectal melanoma tumors, however, anorectal melanomas staging and treatment protocols are also useful for these tumors. .,24,25 $^{9}$ Recently, immunotherapy also shows success in treating melanomas in Japan. It has been shown that Nivolumab (OPDIVO), an antibody to programmed death (PD-1) is beneficial in controlling metastasis of amelanotic anorectal melanoma. ${ }^{26}$ Surgery in combination with radiotherapy and adjuvant immunotherapy, like interferon, was reported to be a choice of treatment for amelanotic anorectal melanoma if the tumor is not metastasized. ${ }^{27,28}$ Laparoscopic abdominoperineal resection (APR) was also shown to be useful in treating anorectal amelanotic melanoma due to its minimally invasive nature. ${ }^{29}$

\section{CASE REPORT}

An 84-year-old Saudi Arabian female patient was diagnosed for chronic calculous cholecystitis and had a laparoscopic cholecystectomy 2 years earlier and discharged in stable condition. This time she was admitted to ER with a complaint of anal mass for 3 months. She had a history of diabetes, hypertension, and hypothyroidism as well. She had no abdominal pain or fever; abdomen was soft and lax with no tenderness or distension. She did not notice any changes in bowl habits, but she noticed fresh blood during defecation. On physical examination there was painful cylindrical mass $(7.0 \times 4.0$ $\mathrm{cm}$ ) prolapsing through the anus, which was pale pinkish in color and was thought to be clinically malignant (figure 1).

Abdomen and pelvic computed tomography (CT) showed rectal wall thickening with an eccentric polypoid lesion of soft tissue density arising from the wall of the rectum predominantly from the left side, which measured around $4.24 \times 6.21 \times 7.25 \mathrm{~cm}$ (craniocaudal $\times$ transverse $\times$ anteroposterior) diameters, respectively (figure 2). The mass was situated about $3.9 \mathrm{~cm}$ from the anal verge with intraluminal projection and subsequent marked reduction of the anorectal caliber. Perirectal fat planes stranding with presacral lymph node enlargement was seen. The largest lymph node on the left side measured around $1.5 \times 1.8 \mathrm{~cm}$ in size (figure $3 . \mathrm{B}$ ), and left inguinal lymphadenopathy was noted (figure 3.A). Both kidneys showed multiple. The liver was enlarged with diffuse fatty infiltration, no focal lesions were seen. These radiological descriptions suggested the anorectal mass was likely to be malignant and recommended for biopsy correlation. CT of the chest was done, which showed a small $(0.77 \times 0.49 \mathrm{~cm})$ nodule in the lower left lobe of the lung that was likely suggestive of metastatic deposit (Figure 3.C). In figure 4 (A and B) contrast enhance axial and coronal magnetic resonance imaging (MRI) of the pelvis with anorectal polypoid mass with marginal and eccentric enhancement is shown. These radiological 


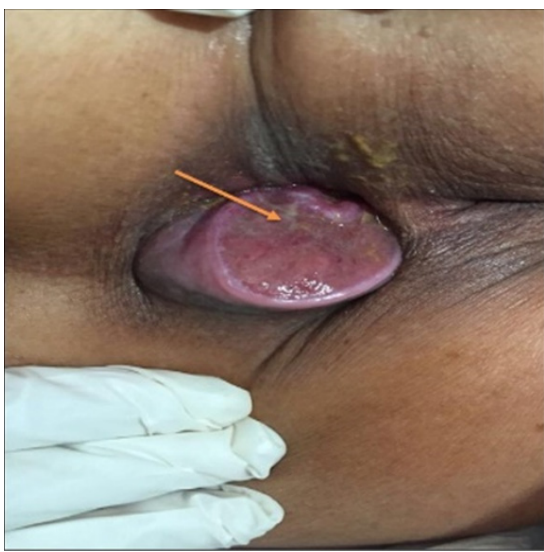

Fig.1: Grossing shows tumor mass extending from the rectum throughout the anus, $4 \mathrm{~cm}$ out (yellow arrow), and tumor mass pinkish white color with surface ulceration.
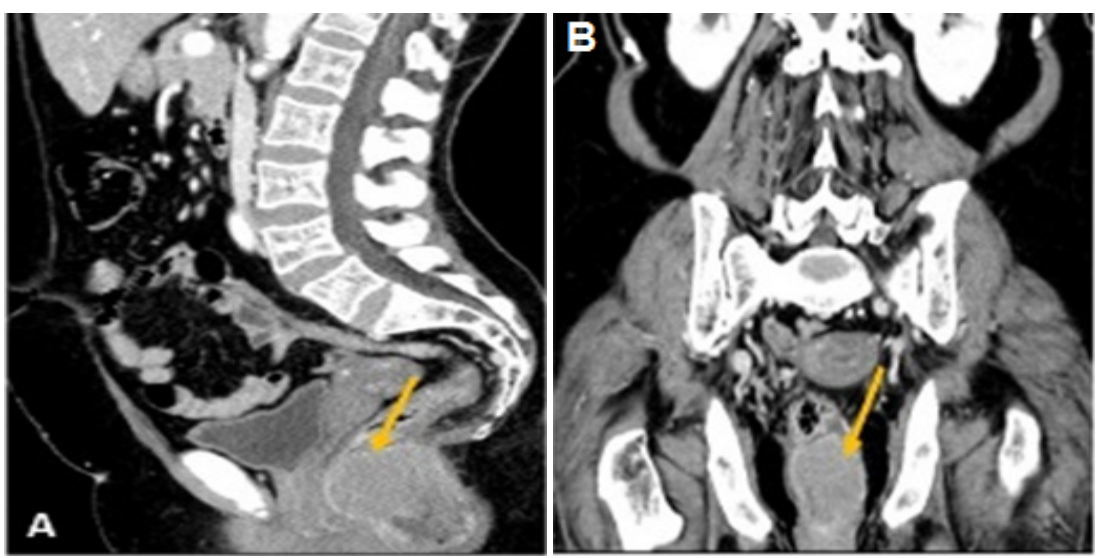

Fig.2: Sagittal (A), and coronal (B) views of abdomen and pelvic CT show cranial caudal extension of anorectal mass (yellow arrow) from the anal verge.
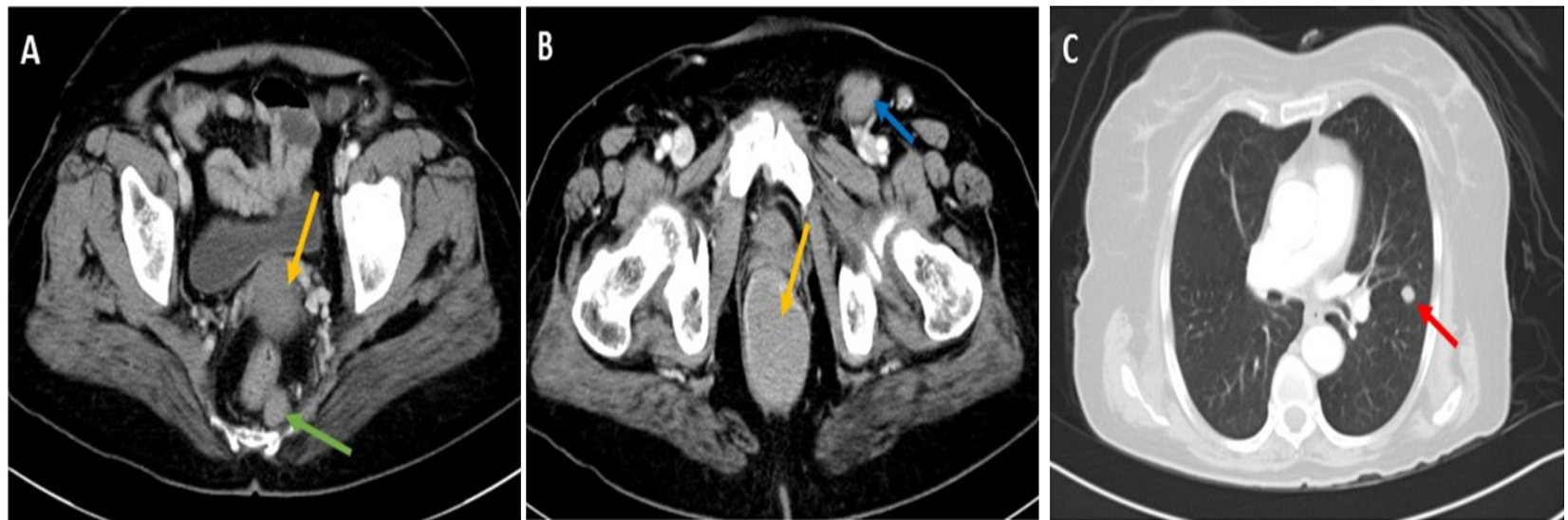

Fig.3: Axial CT of pelvis and chest show rectal wall thickening with an eccentric polypoid lesion of soft tissue density (Fig A \& B yellow arrow) arising from the wall of the rectum predominantly from the left side with subsequent marked reduction of the anorectal caliber. Left inguinal lymph node (Fig. B, blue arrow) and presacral lymph node (Fig A, green arrow) enlargement was also seen. CT of the chest shows a small nodule (Fig $\mathrm{C}$, red arrow) in the lower lobe of the left lung likely representing metastatic deposit.
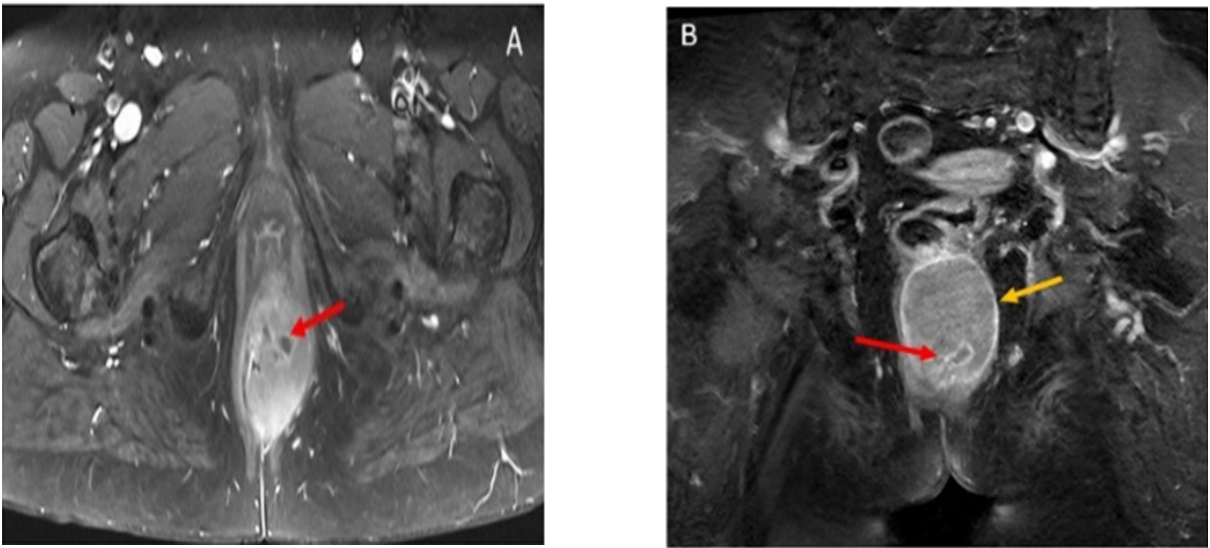

Fig.4: Contrast enhance axial (A) and coronal MRI of pelvis (B) show anorectal polypoid mass with marginal (yellow arrow) and eccentric (red arrow) enhancement. 

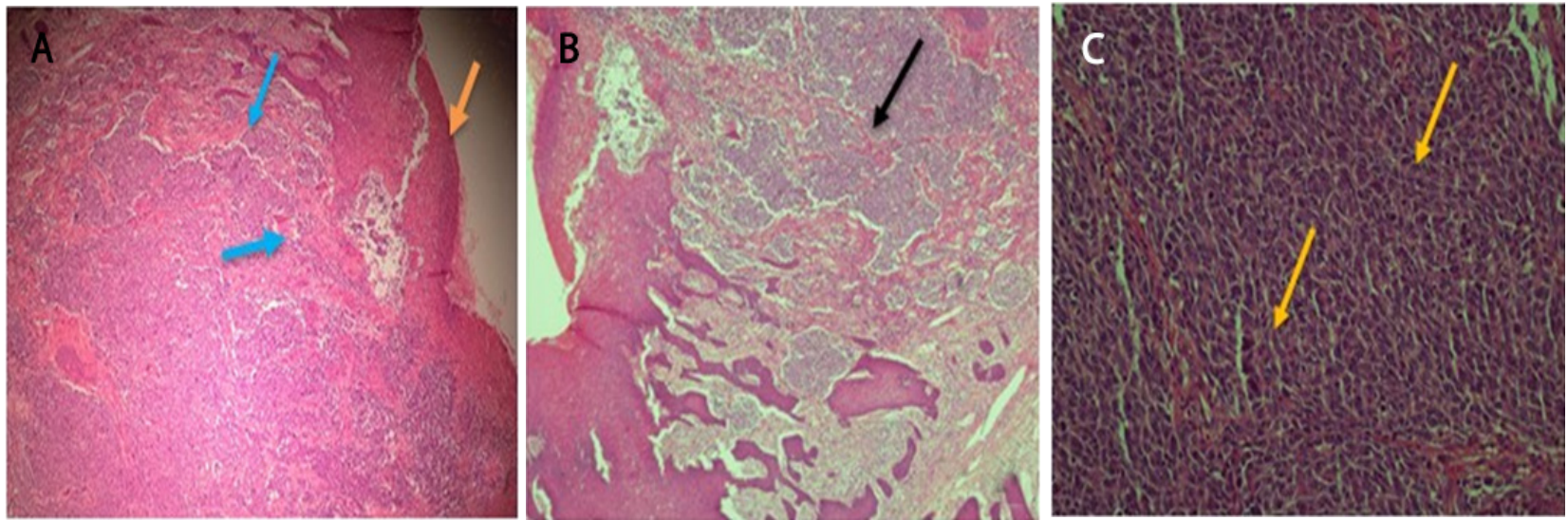

Fig.5: (A). H \& E stained microscopic pictures showing skin with hyperplastic squamous epithelium with surface ulceration (yellow arrow). Extensive tumor growth beneath the surface squamous epithelium (blue arrow). (B) The dermis and underlining tissue are showing (10x) infiltration by malignant sheets and nests of ovoid and spindle shape cells (black arrows); (C), with prominent and high mitotic figures (yellow arrow). The nuclei are hyper chromatic with some prominent nucleoli (40x).
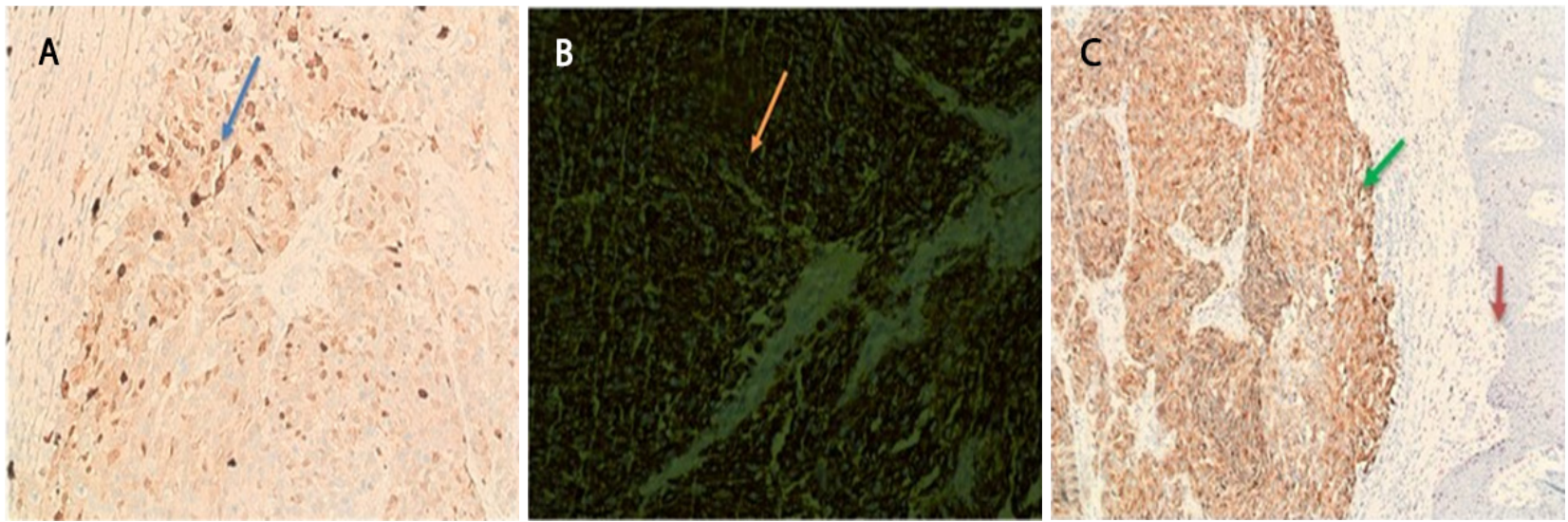

Fig.6: (A) Immunostaining for S-100 shows positivity in tumor cells; (B). Immunostaining for HMB-45 shows positivity in tumor cells. (C) Melan A- is positive in tumor cells (green arrow). The epidermis is negative (Red arrow).

descriptions suggested of malignant nature of this tumor. Colonoscopy was also performed to see occult lesion or mucosal changes. Rectal biopsy was obtained from the primary tumor site for histopathological evaluation.

For the histological evaluation, two pieces of soft tissue were received in formalin. The tissues had a solid grayish white surface, covered with ulcerated mucosa measuring $2.5 \times 1.0 \times 1.0 \mathrm{~cm}$. Microscopic examination revealed a piece of skin with hyperplastic squamous epithelium with surface ulceration (figure 5.A). The dermis and underlining tissue were infiltrated by sheets and nests of malignant ovoid and spindle shape cells. The tumor cells had hyperchromatic nuclei with prominent nucleoli and high mitotic activity (Figure 5.B and C). Immunohistochemistry showed immunoreactivity for melanocytic markers such as Human Melanoma Black-45 (HMB-45), and melanoma-associated protein A (Melan-A/MART-1), and also positive for S-100 (figure.6) and negative for P63, CK 5/6, and Pan CK (figure7).

\section{DISCUSSION}

Melanomas are known to occur on any region of the body, wherever melanocytes present, for example places such as the epidermis, eyes, nasal cavity, oropharynx, vagina, urinary tract, rectum, and anus. The median age for anorectal melanoma cases is 66 years at the time of diagnosis, with a female predominance up to $60 \%{ }^{30} \mathrm{In}$ 

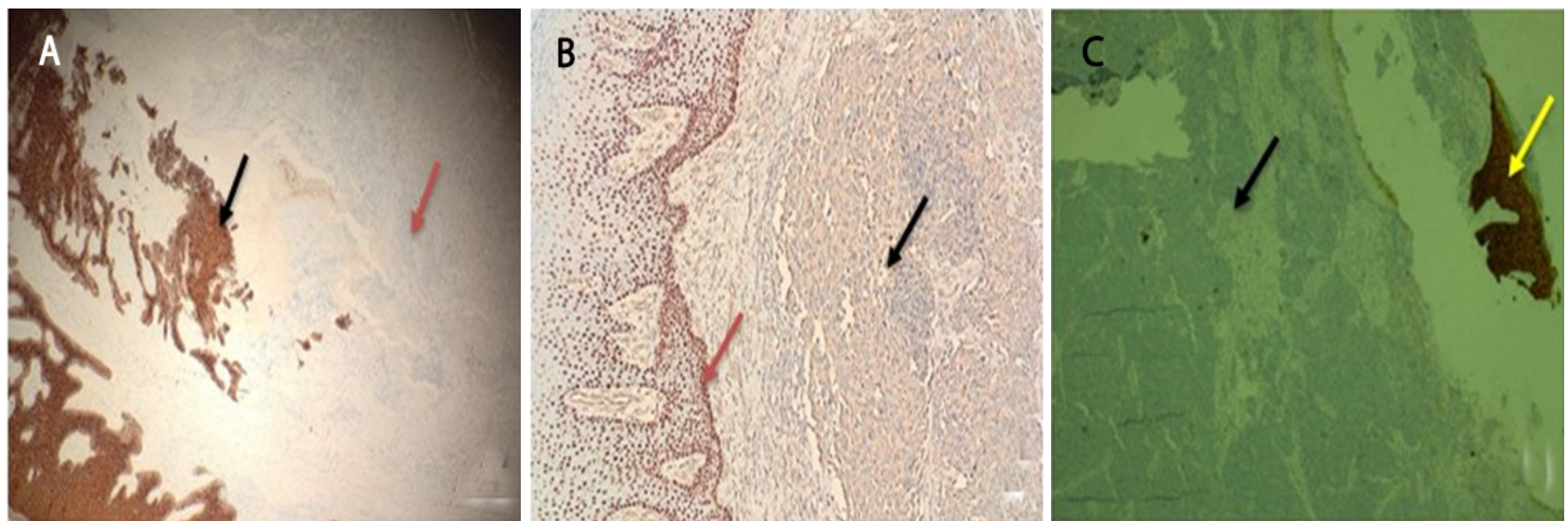

Fig.7: (A) Pan CK is negative in tumor cells (red arrow), and positive in epidermal squamous cells (black arrow). (B) P63 positive nucleus in the normal epidermal cells (red arrow), and negative in tumor cells (black arrow). (C) CK-5/6 is negative in tumor cells (black arrow), and positive in epidermal cells (yellow arrow), suggesting that this is not an epithelial tumor.

a retrospective analysis of 61 cases of anorectal malignant melanomas during 2005-2014, Tariq and colleagues have reported that around $21 \%$ of cases were completely amelanotic. ${ }^{31}$ Examination by CT was used to detect metastasis of this tumor to distant organs such as liver, lungs, and kidneys. Also, the most common sites for metastases are inguinal and pre-sacral lymph nodes as we have observed in this case. ${ }^{32-34}$ Khaled and co-workers have reported a case of amelanotic anorectal malignant melanoma with satellite lesions or an unusual metastatic deposit in the vulva. ${ }^{35}$ Amelanotic melanomas also were reported on body parts such as in the middle ear, ${ }^{21}$ on the upper arm and the shoulder, ${ }^{36}$ in the esophagus, ${ }^{37}$ in duodenum, ${ }^{38}$ on perineum and perianal sites, ${ }^{39}$ on penis, ${ }^{40}$ on female urethra, ${ }^{41}$ and in vagina, breasts, and vulva. ${ }^{42-44}$ Further, amelanotic forms of acral melanomas, hallux (subungual amelanotic melanoma), subungual acrolentiginous melanoma, conjunctival melanoma, irido-ciliary ring melanoma, choroidal melanoma, melanoma of the nasal cavity, melanoma of the tongue, and intracranial amelanotic melanoma involving brain were also reported previously. ${ }^{45-54}$

Distinction of amelanotic anorectal melanoma from lymphoma, undifferentiated carcinoma, and gastrointestinal stromal tumor (GIST) is difficult on the basis of histological criteria alone. HMB-45 and Melan-A are useful in the differential diagnosis between granular cell tumor and malignant melanoma. ${ }^{55}$ Abnormal expression of immunohistochemical stains such as vimentin, cytokeratin, and c-Kit (CD117) further increases the risk of misdiagnosis. ${ }^{23}$ However, activating c-Kit mutations have been associated with the pathogenesis of malignant melanoma, which are commonly found in leukemia and gastrointestinal stromal tumors. ${ }^{56}$ There are few reports of amelanotic melanomas with S-100 negative and c-Kit positive, one such case that confused clinicians, was from Japan that was difficult to diagnose between amelanotic melanomas and GIST of the anorectum. ${ }^{23}$ In their case the authors reported that the anorectal tumor was positive for vimentin and c-Kit, and negative for S-100, however, an excisional biopsy of the inguinal lymph node showed positive for S-100, Melan-A, HMB-45, and tyrosinase. And upon repeating the immuno-histochemistry of the anorectal tumor, this was positive for Melan-A, HMB45 , and tyrosinase but negative for S-100. Immunological markers are very important to make the diagnosis accurately. We have shown the prevalence of immuno-markers that were used in the histopathology for differential diagnosis of anorectal melanomas in table 1. As shown, S100 and HMB45 are positive in all cases tested, and cytokeratin is negative in all cases of anorectal melanomas. Immuno-staining with melanoma markers such as protein S-100, melanoma antigen HMB-45, and vimentin are important for final diagnosis in amelanotic melanoma, and most of the times it is positive. Whereas, positive staining for carcinoembryonic antigen (CEA), cytokeratin, epithelial membrane antigen (EMA or MUC1) is suggestive of adenocarcinoma. ${ }^{22,57}$ Canales and Blesa ${ }^{22}$ have reported that anorectal melanomas are strongly positive for vimentin, CD117 (C-kit), S-100 protein, and 
Table 1: Prevalence of Immuno-Markers in Anorectal Melanomas

\begin{tabular}{|c|c|c|c|c|c|c|c|c|}
\hline Vimentin & Melan-A & Cytokeratin & Ki-67 & НМB-45 & S-100 & P53/P63 & C-Kit & Reference \\
\hline Positive & Positive & Negative & Positive $(60 \%)$ & Positive & Positive & ND & $\begin{array}{l}\text { Diffusely } \\
\text { Positive }\end{array}$ & 22 \\
\hline ND & ND & ND & ND & Positive & Positive & ND & ND & 7 \\
\hline ND & Positive & ND & ND & Positive & Positive & ND & ND & 26 \\
\hline ND & ND & ND & ND & ND & Positive & ND & ND & 6 \\
\hline ND & Positive & ND & ND & ND & Positive & ND & Positive & 27 \\
\hline ND & Positive & ND & ND & Positive & Positive & ND & ND & 59 \\
\hline Positive & ND & Negative & Positive $(60 \%)$ & Positive & Positive & P53-Positive & Negative & 16 \\
\hline Positive & Positive & ND & ND & Positive & Positive & ND & Positive & 23 \\
\hline ND & Positive & ND & Positive & Positive & Positive & ND & ND & 32 \\
\hline ND & Positive & ND & ND & Positive & Positive & ND & ND & 29 \\
\hline ND & ND & ND & ND & Positive & Positive & P63-Negative & Positive & 34 \\
\hline ND & Positive & ND & ND & Positive & Positive & ND & ND & 33 \\
\hline ND & 3/4-POS & 3/3-NEG & ND & 5/5-POS & 6/6-POS & ND & ND & 60 \\
\hline
\end{tabular}

Melan-A; however, HMB-45 stain was focally positive. Stains for cytokeratin, smooth muscle actin, desmin, h-caldesmon, chromogranin, synaptophysin, and CD34 were negative. The Ki67 proliferation index was $60 \%$. In another case studied an anorectal melanoma was misdiagnosed as a GIST because it was positive for CD56, S100, and CD117; however, further confirmation with HMB-45 and Melan-A led to the correct diagnosis. ${ }^{58}$

\section{CONCLUSION}

This is the first case of amelanotic anorectal melanoma reported from Saudi Arabia. Amelanotic anorectal melanomas spread by lymphatics to regional nodes, and hematogenously to the lungs and to other organs. Thickness of the tumor appears to be correlated with the clinical outcome in anorectal melanoma. Thickness of $4.0 \mathrm{~mm}$ or more is more prone to relapse, metastasis, and low disease-free survival rate. Thus, this case showed little promise of survival as the tumor was significantly large and she was discharged on her own will.

\section{ACKNOWLEDGMENT}

The authors wish to thank Ms. Rowa Abbas Bakhsh of Al-Noor Specialty Hospital Makkah, for her help with histopathology, and the staff of the Deanship of the Scientific Research (DSR), Umm-Al-Qura University, Makkah, for their continuous support.
Grant Support: This study is partly supported by a grant from The Deanship of Scientific Research, Umm-Al-Qura University, Makkah, to Dr.MM. Taher (Code. No. 43509008).

\section{ETHICAL APPROVAL}

There is nothing to be declared.

\section{CONFLICT OF INTEREST}

The authors declare no conflict of interest related to this work.

\section{REFERENCES}

1. Chang AE, Karnell LH, and Menck HR. The National Cancer Data Base report on cutaneous and noncutaneous melanoma: a summary of 84,836 cases from the past decade. Cancer 1998;83:1664-78. doi:10.1002/ (SICI) 1097-0142(19981015)83:8<1664::AIDCNCR23>3.0.CO;2-G.

2. Brady MS, Kavolius JP, and Quan SH. Anorectal melanoma. A 64-year experience at Memorial Sloan-Kettering Cancer Center. Dis Colon Rectum 1995;38:146-51. doi:10.1007/BF02052442.

3. Koch SE, and Lange JR. Amelanotic melanoma: The great masquerader. J Am Acad Dermatol 2000; 42:731-4. doi:10.1067/mjd.2000.103981.

4. Cheung WL, Patel RR, Leonard A, Firoz B, Meehan SA. Amelanotic melanoma: a detailed morphologic analysis with clinicopathologic correlation of 75 cases. J Cutan Pathol 2012;39:33-9. doi:10.1111/ j.1600-0560.2011.01808.x.

5. Jaimes N, Braun RP, Thomas L, Marghoob AA. 
Clinical and dermoscopic characteristics of amelanotic melanomas that are not of the nodular subtype. J Eur Acad Dermatol Venereol 2012;26:591-6. doi:10.1016/j.jaad.2015.02.1117.

6. Hillenbrand A, Barth TF, Henne-Bruns D, Formentini A. Anorectal amelanotic melanoma. Colorectal Dis 2008;10:612-5. doi:10.1111/j.1463-1318.2007.01400.x.

7. Sahoo MR, Gowda MS, and Kaladagi RM. Primary amelanotic melanoma of the rectum mimicking adenocarcinoma. Am J Case Rep 2013;14:280-3. doi:10.12659/AJCR.889089.

8. Gualandri L, Betti R, and Crosti C. Clinical features of 36 cases of amelanotic melanomas and considerations about the relationship between histologic subtypes and diagnostic delay. J Eur Acad Dermatol Venereol 2009;23:283-7. doi:10.1111/j.1468-3083.2008.03041.x.

9. Belli F, Gallino GF, Lo Vullo S, Mariani L, Poiasina E, Leo E. Melanoma of the anorectal region. The experience of the National Cancer Institute of Milano. Eur J Surg Oncol 2009;35:757-62. doi:10.1016/j. ejso.2008.05.001.

10. Negbenebor NA, Feller E. A rare case of amelanotic anorectal melanoma. R I Med J 2017;100:31-2.

11. Bleier J. Primary Anorectal Amelanotic Melanoma Presenting as Internal Hemorrhoids. Gastroenterol Hepatol (NY) 2009;5:519-20.

12. Chiaravalloti A, Banki A. An Elusive Amelanotic Melanoma and Review of Dermoscopic Findings. $J$ Drugs Dermatol 2017;16:1164-5.

13. Kaizer-Salk KA, Herten RJ, Ragsdale BD, Sengelmann RD. Amelanotic melanoma: a unique case study and review of the literature. BMJ Case Rep 2018;2018. pii:bcr-2017-222751. doi:10.1136/bcr-2017-222751.

14. Elmets CA, Ceilley RI. Amelanotic melanoma presenting as a pyogenic granuloma. Cutis 1980;25:164-8.

15. Rao AG, Babu VA, Koppada D, Haritha M, Chandana P, Swapna, et al. Amelanotic Melanoma in the Vicinity of Acquired Melanocytic Nevi and not Arising from Agminated Melanocytic Nevi: Masquerading as Pyogenic Granuloma. Indian J Dermatol 2016;61:122. doi:10.4103/0019-5154.174135.

16. Terada T. Primary Epithelioid Amelanotic Malignant Melanoma of the Rectum: A Differential Diagnosis. $J$ Gastrointest Canc 2012;43(Suppl 1):S221-S5. doi:10.1007/s12029-012-9384-3.

17. Joshi PV, Lele VR, Aland NJ, Bhat G, Ajinkya SP, Patel RP. Malignant amelanotic melanoma - A diagnostic surprise: Flurodeoxyglocose positron emission tomography-Computed tomography and immunohistochemistry clinch the 'final diagnosis'. J Can Res Ther 2012;8:451-3. doi:10.4103/0973-1482.103533.

18. Goldberg DJ. Amelanotic melanoma presenting as Bowen's disease. J Dermatol Surg Oncol 1983;9:902-4.

19. Aksu Çerman A, Demirçay Z, Demirkesen C. Amelanotic melanoma presenting as contact dermatitis. Eur $J$
Dermatol 2010;20:857-8. doi:10.1684/ejd.2010.1094.

20. Shields JA, Shields CL, Lally SE, Milman T, Eagle RC. Iris Melanoma in a Child Simulating Juvenile Xanthogranuloma. Middle East Afr $J$ Ophthalmol 2018;25:115-7. doi:10.4103/meajo.MEAJO_7_18.

21. Uchida M, and Matsunami T. Malignant amelanotic melanoma of the middle ear. Arch Otolaryngol Head Neck Surg 2001;127:1126-8. doi:10.1001/archotol.127.9.1126.

22. Laforga Canales JB, Gasent Blesa JM. Amelanotic Anorectal Malignant Melanoma: Case Report with Immunohistochemical Study and Literature Review. Case Rep Oncol 2009;2:30-7. doi:10.1159/000204788.

23. Tsuchihashi $\mathrm{H}$, Ito A, Tsukada $\mathrm{H}$, Hasegawa $\mathrm{H}$, Naitoh H, Hanasawa K, et al. A case of amelanotic anorectal malignant melanoma mimicking gastrointestinal stromal tumor. Gan To Kagaku Ryoho 2011;38:2659-62.

24. Balch CM, Gershenwald JE, Soong SJ, Thompson JF, Atkins MB, Byrd DR, et al. Final version of 2009 AJCC melanoma staging and classification. J Clin Oncol 2009;27:6199-206. doi:10.1200/JCO.2009.23.4799.

25. Breslow A. Thickness, cross-sectional areas and depth of invasion in the prognosis of cutaneous melanoma. Ann Surg 1970;172:902-8. doi:10.1097/00000658197011000-00017.

26. Tokuhara K, Nakatani K, Tanimura H, Yoshioka K, Kiyohara T, Kon M. A first reported case of metastatic anorectal amelanotic melanoma with a marked response to anti-PD-1 antibody nivolumab: A case report. Int J Surg Case Rep 2017;31:188-92. doi:10.1016/j.ijscr.2017.01.028.

27. Hay A, Liong J, Kumar D, and Glees J. A striking response of anorectal melanoma to radiotherapy (locoregional disease confined to perineum and anal canal). Ann $R$ Coll Surg Engl 2010;92:e10-e12. doi:10.1308/147870810X476647.

28. Weyandt GH, Eggert AO, Houf M, Raulf F, Brocker EB, Becker JC. Anorectal melanoma: surgical management guidelines according to tumour thickness. $\mathrm{Br} J$ Cancer 2003;89:2019-22. doi:10.1038/sj.bjc.6601409.

29. Hiraki S, Kuwahara T, Harada T, Kawaoka T, Fukuda S. A Case of Anorectal Amelanotic Malignant Melanoma. Gan To Kagaku Ryoho 2015;42:2256-8.

30. Cagir B, Whiteford MH, Topham A, Rakinic J, Fry RD. Changing epidemiology of anorectal melanoma. Dis Colon Rectum 1999;42:1203-8.

31. Tariq MU, Ud Din N, Ud Din NF, Fatima S, Ahmad Z. Malignant melanoma of anorectal region: a clinicopathologic study of 61 cases. Ann Diagn Pathol 2014;18:27581. doi:10.1016/j.anndiagpath.2014.08.002.

32. Fillmann LS, Fillmann EEP, Fillmann HS, de Oliveira JK, Parizotto JFB, Scolaro BL, et al. Anorectal melanoma: review of diagnosis and treatment based on a case report. J Coloproctol (Rio J.) 2012;32. 
33. Svoboda SS, Attuwaybi B. Anorectal melanoma treated with abdominoperineal resection. Clin Case Rep 2018;6:2174-7. doi:10.1002/ccr3.1784.

34. Serra M, Santos T, Martins M, Sardo L. Amelanocytic anorectal malignant melanoma-Case report. Int J Surg Case Rep 2019;55:164-7. doi:10.1016/j. ijscr.2019.01.029.

35. Khaled A, Hammami H, Fazaa B, Kourda N, Kamoun MR, Ben Jilany S, et al. Primary amelanotic anorectal melanoma: an uncommon neoplasia with poor prognosis. Pathologica 2009;101:126-9.

36. Coras B, Hohenleutner S, Raff K, Landthaler M, Hohenleutner U. The "red melanoma"--a rare form of amelanotic malignant melanoma. J Dtsch Dermatol Ges 2004;2:597-600.

37. De Simone P, Gelin M, El Nakadi I. Amelanotic malignant melanoma of the esophagus. Report of a case. Minerva Chir 2006;61:45-9.

38. Kilambi R, Singh AN, Dash NR, Madhusudhan KS, Das P. Primary giant aggressive amelanotic duodenal melanoma. Ann R Coll Surg Engl 2017;99:e131-e4. doi:10.1308/rcsann.2016.0323.

39. Zamurovic M, Soldo V, Cutura N, Perisic Z. Amelanotic malignant melanoma of the perineum: a case report. Eur J Gynaecol Oncol 2013;34:269-70.

40. Nejc D, Piekarski J, Pasz-Walczak G, Wroński K, Pluta P, Jeziorski A. The first description of sentinel node biopsy in a patient with amelanotic melanoma of the glans penis. Melanoma Res 2005;15:565-9.

41. Yoshii T, Horiguchi A, Shirotake S, Tobe M, Tasaki $\mathrm{S}$, Hayakawa $\mathrm{M}$, et al. Case of primary amelanotic malignant melanoma of the female urethra. Nihon HinyōKika Gakkai Zasshi 2010;101:734-7.

42. Biswas A, Goyal S, Jain A, Suri V, Mathur S, Julka PK, et al. Primary amelanotic melanoma of the breast: combating a rare cancer. Breast Cancer 2014;21:236-40. doi:10.1007/s12282-010-0231-8.

43. Ulmer A, Dietl J, Schaumburg-Lever G, Fierlbeck G. Amelanotic melanoma of the vulva simulating lichen sclerosus et atrophicus. Hautarzt 1996;47:854-7.

44. Oguri H, Izumiya C, Maeda N, Fukaya T, Moriki T. A primary amelanotic melanoma of the vagina, diagnosed by immunohistochemical staining with HMB45 , which recurred as a pigmented melanoma. $J$ Clin Pathol 2004;57:986-8. doi:10.1136/jcp.2004.016220

45. Sbai MA, Boussen M, Mankai I, Souissi M, Day SC, Korbi A, et al. Amelanotic malignant melanoma of the great toe. Tunis Med 2010;88:130-1.

46. Gosselink CP, Sindone JL, Meadows BJ, Mohammadi A, Rosa M. Amelanotic subungual melanoma: a case report. J Foot Ankle Surg 2009;48:220-4. doi:10.1053/j.jfas.2008.11.012.

47. Guarneri C, Bevelacqua V, Semkova K, Tchernev G, Tempel S, Wollina U. Subungual acrolentiginous amelanotic melanoma treated with amputation of the distal and middle phalanges. Wien Med Wochenschr 2013;163:368-71. doi:10.1007/s10354-013-0194-4.

48. Damani MR, O'Brien JM. Amelanotic Conjunctival Melanoma. JAMA Ophthalmol 2016;134:e153568. doi:10.1001/jamaophthalmol.2015.3568

49. Aziz HA, Modi YS, Plesec TP, Singh AD. Amelanotic Irido-Ciliary Ring Melanoma: A Clinicopathological Correlation. Ocul Oncol Pathol 2016;2:1535. doi:10.1159/000441725

50. Giuliari GP, Connor A, Simpson ER. Amelanotic choroidal melanoma. Lancet 2011;377:p848. doi:10.1016/S0140-6736(10)60815-X.

51. Gupta S, Pant MC, Husain N, Sundar S, Khan H. Primary a.melanotic melanoma of the nasal cavity: a case report. Ear Nose Throat J 2014;93:E12-4.

52. Venugopal M, Renuka I, Bala GS, Seshaiah N. Amelanotic melanoma of the tongue. J. Oral Maxillofac. Pathol 2013;17:113-5. doi:10.4103/0973-029X.110699.

53. Ma J, Zhang Z, Li S, Chen X, Wang S. Intracranial amelanotic melanoma: a case report with literature review. World J Surg Oncol 2015;13:182. doi:10.1186/s12957-015-0600-z.

54. Karakis I, McGeeney B, Demierre MF, Thiele JJ, Wolpowitz D, Bhawan J. Acquired hypopigmentation (leukoderma) as a presenting feature of metastatic amelanotic melanoma with brain involvement. Arch Neurol 2007;64:1786-7. doi:10.1186/s12957015-0600-z.

55. Gleason BC, and Nascimento AF. HMB-45 and Melan-A are Useful in the Differential Diagnosis Between Granular Cell Tumor and Malignant Melanoma. Am J Dermatopathol 2007;29:22-7. doi:10.1097/01.dad.0000249888.41884.6c.

56. RowD,WeiserMR.Anorectalmelanoma.ClinColonRectal Surg 2009;22:120-6. doi:10.1055/s-0029-1223844.

57. Ben-Izhak O, Levy R, Weill S, Groisman G, Cohen H, Stajerman S, et al. Anorectal malignant melanoma. A clinicopathologic study, including immunohistochemistry and DNA flow cytometry. Cancer 1997;79:18-25.

58. Seya T, Tanaka N, Shinji S, Shinji E, Yokoi K, Horiba $\mathrm{K}$, et al. Case of rectal malignant melanoma showing immunohistochemical variability in a tumor. J Nippon Med Sch 2007;74:377-81. doi:10.1272/jnms.74.377.

59. Deo AK, Shan X-H, Chen J-H. Anorectal Melanoma: Radiologic-Pathologic Correlation. IOSR J Dental Med Sci 2015;14:12-20. doi:10.9790/0853-14931220.

60. Atak I. Anorectal Malignant Melanoma: Retrospective Analysis of Six Patients and Review of the Literature. Prague Med Rep 2018;119:97-106. doi:10.14712/23362936.2018.9. 